\title{
Bioactive glass doped with calcium bromide to inhibit multi-species oral biofilm
}

Noronha Oliveira $\mathrm{M}^{\star 1}$, Galarraga-Vinueza ME${ }^{1}$, Mesquita-Guimarães $\mathrm{J}^{2}$, Henriques B2, Magini RS'1, Fredel MC², Teughels $\mathrm{W}^{3}$, Souza JCM1 ${ }^{1}$ Center for Education and Research on Dental Implants (CEPID), Federal University of Santa Catarina, Florianópolis, Brazil ${ }^{2}$ Ceramic and Composite Materials Research Group (CERMAT), Federal University of Santa Catarina, Florianópolis, Brazil ${ }^{3}$ Department of Oral Health Sciences, University Hospitals Leuven, Katholieke Universiteit Leuven, Leuven, Belgium

\section{Topic: Basic research}

\section{Background}

Bioactive glass has shown excellent osteogenic and angiogenic effects for bone regenerative procedures although its anti-biofilm potential has not been validated against multi-species biofilms involved in early tissue infections.

\section{Aim/Hypothesis}

The present study aimed to evaluate the anti-biofilm effect of 58 $S$ bioactive glass embedding calcium bromide compounds at different concentrations.

\section{Materials and Methods}

Bioactive glass containing 5 or 10 wt \% CaBr2 was synthesized by alkali sol-gel method and then analyzed by physicochemical and scanning electron microscopy (SEM). The anti-biofilm potential was assessed by microbiological assays using optical density, real time q-PCR, and SEM.

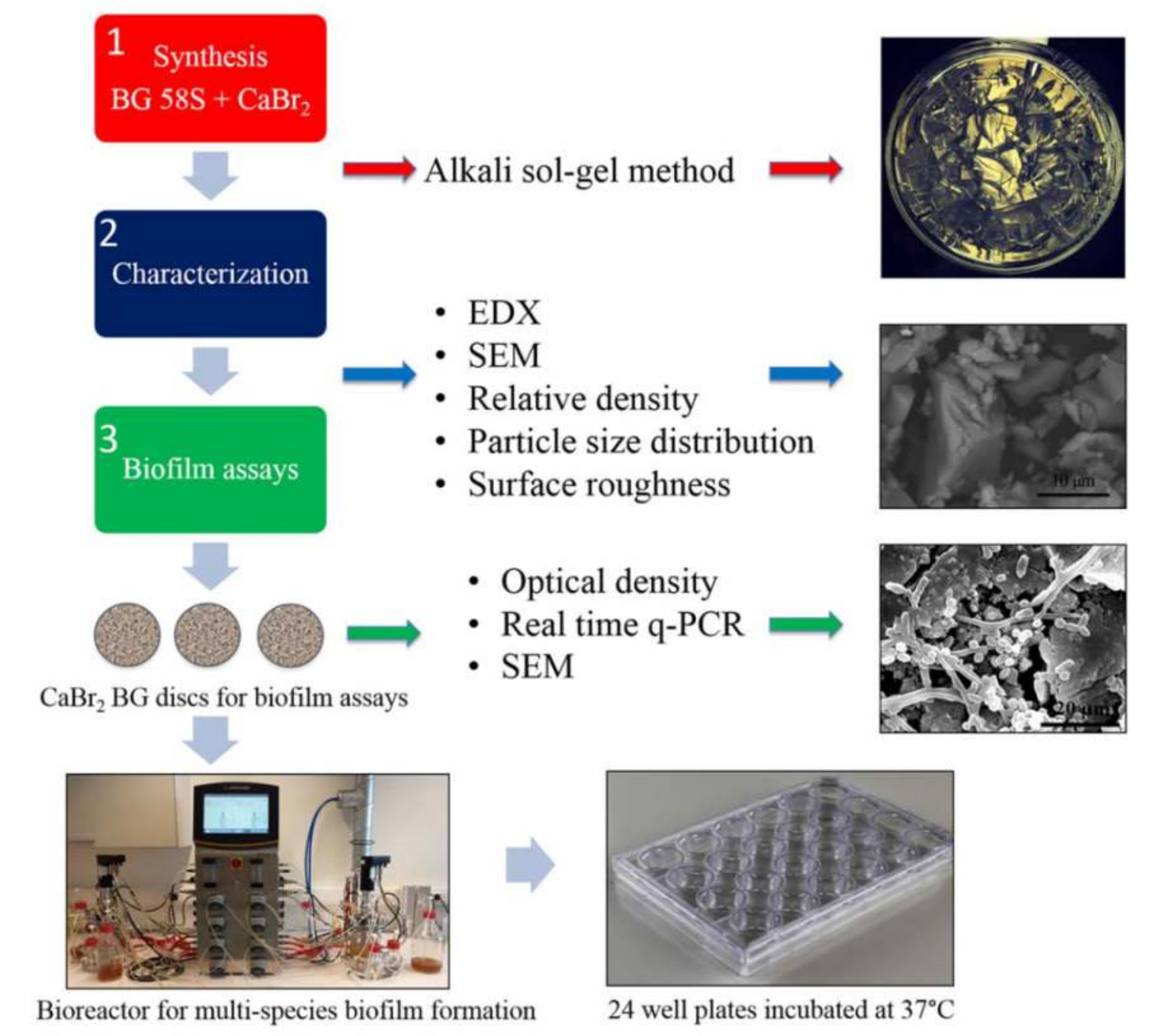

Figure 1 - Schematic diagram showing the followed methodology to assess biofilm inhibition.

\section{Results}

Bioactive glass particles showed accurate chemical composition and an angular shape with a bimodal size distribution ranging from 0.6 to $110 \mathrm{~mm}$. A significant anti-biofilm effect was recorded for 5 wt \% $\mathrm{CaBr} 2$ doped bioactive glass against $\mathrm{S}$. mitis, $\mathrm{V}$. parvula, $S$. gordoni, $A$. viscosus, $F$, nucleatum, and $P$. gingivalis. Such species are involved in the biofilm structure related to infections on hard and soft tissues in the oral cavity.

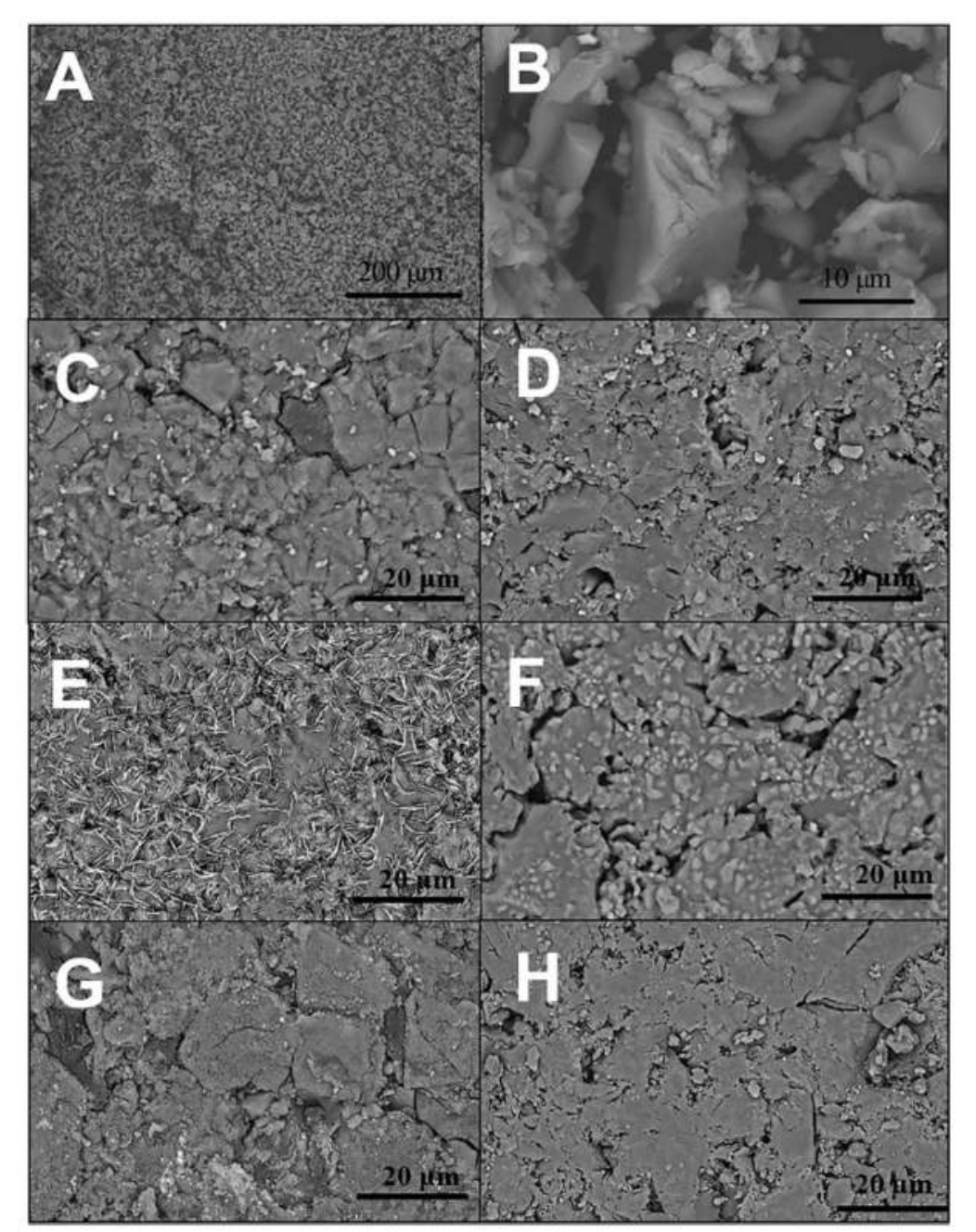

Figure 2 - SEM images of BG 58 S 5 wt \% CaBr2 doped powder (A and B), BG $58 \mathrm{~S}$ discs before thermal treatment (C) 0 , (E) 5 , and $(G) 10 \mathrm{wt} \% \mathrm{Br}$ and $(\mathrm{D})$, (F) 5, and (H) $10 \mathrm{wt} \% \mathrm{CaBr} 2 \mathrm{BG}$ $58 \mathrm{~S}$ discs after thermal treatment up to $11508 \mathrm{C}$.

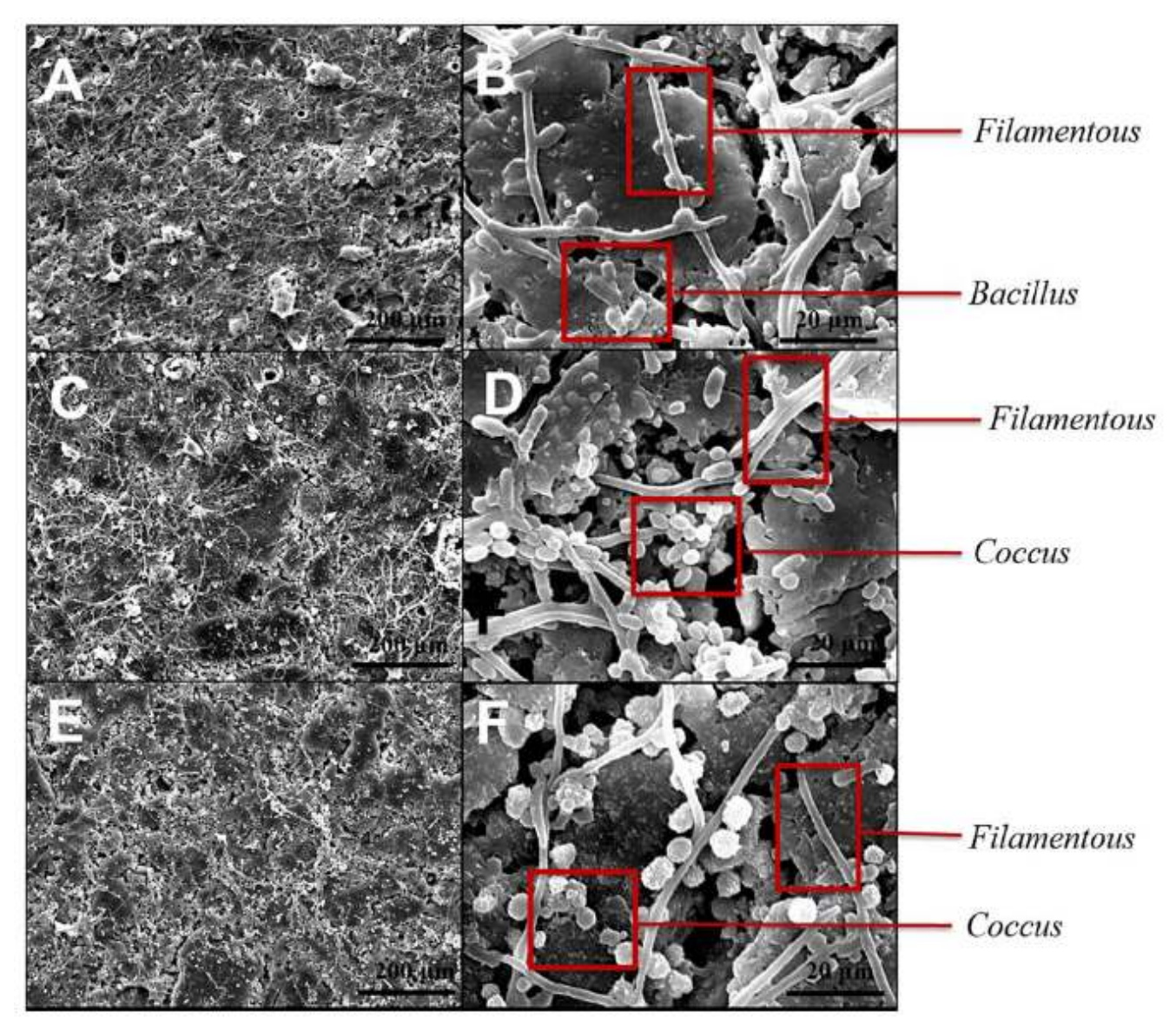

Figure 3 - SEM images of multi-species biofilm adherence on BG58S discs with 0 wt $\% \mathrm{CaBr}_{2}(\mathrm{~A}, \mathrm{~B}), 5$ wt $\% \mathrm{CaBr}_{2}(\mathrm{C}, \mathrm{D})$ and 10 wt $\% \mathrm{CaBr}_{2}(\mathrm{E}, \mathrm{F})$.

\section{Conclusions and Clinical implications}

The anti-biofilm potential of bioactive glasses can be improved by incorporating active compounds such as bromides for bone healing and infection treatment.

\section{References}

1. Jones JR. Review of bioactive glass: From Hench to hybrids. Acta Biomater 2013;9:4457-4486.

2. Hench LL, Jones JR. Bioactive glasses: Frontiers and challenges. Front Bioeng Biotechnol 2015;3:194.

3. Galarraga-Vinueza ME, Mesquita-Guimarães J, Magini RS, Souza JCM, Fredel MC, Boccaccini AR. Anti-biofilm properties of bioactive glasses embedding organic active compounds. J Biomed Mater Res A 2017;105: 672-679. 